\title{
The Challenges of Water Scarcity and the Future of Food Security in the United Arab Emirates (UAE)
}

\author{
Suzan M. Shahin *, Mohammed A. Salem \\ College of Food \& Agriculture, United Arab Emirates University, Al Ain, United Arab Emirates
}

Copyright (C) 2015 Horizon Research Publishing All rights reserved.

\begin{abstract}
This paper will provide an inside of the situation of the United Arab Emirates (UAE) as a country that has limited fresh water resources. This fact in conjunction with the sever depletion of groundwater aquifers (which contribute to $70 \%$ of total water resources in the UAE). The sharp population growth could create critical challenges in providing the irrigation requirements for the agricultural sector, required to reach food security in this country. The main purpose of this work is to investigate whether the future watering requirements for crop production purposes could be met and sustained in 2030 . This would be done through, reviewing the available irrigation resources and predicting the projected demand, required to cover the agricultural sector. The conclusion indicates that, the total predicted watering requirement depending on the groundwater resources for crops production would be approximately 2198 million $\mathrm{m}^{3} /$ year. On the other hand, the year 2030 could be the first year with no more supply from groundwater resources. Leaving the future of the agricultural sector in a real critical situation, that can best be mitigated by adopting the best sustainable agricultural practices.
\end{abstract}

Keywords Agricultural Sector, Food Security, Groundwater Depletion, Irrigation Resources, Population Growth, Water Scarcity, United Arab Emirates (UAE), 2030 .

\section{Introduction}

The UAE is a young country, with total area around $82,880 \mathrm{~km}^{2}$ and total population estimated to be 9,346 million in 2013 [1]. It is located in southern part of the Arabian Peninsula and opens into two coasts; Gulf of Oman in the east and Arabian Gulf in the west [2].

Similar to any country located in the arid region, the climate is characterized by very high summer temperatures reaching $46^{\circ} \mathrm{C}$ in average with high humidity rate along the coastal areas reaching around 100\% [3]. Despite, the high evaporation rates, precipitation rates are low and irregular, with average annual rainfall not exceeding $160 \mathrm{~mm}$ [4].

In general, the soil texture is classified as sandy soil $[5,6]$, and thus has high water permeability rate, low water holding capacity, low water moisture content, poor nutrients availability, and consequently low fertility rate [7].

Although, there are many difficulties related to the climatologically conditions and the physical characteristics of the soil in the country, however, huge areas have been converted, over a very short period, from deserts into green lands. For this reason, enormous amounts of water has been used; in order to make the impossible dream a possible one $[2,4,8]$.

The main objective of this work is to review the available irrigation resources in the UAE and to represent the watering requirements for the agricultural sector. Also, to highlight the huge competition between this sector and the forestry sector on using the limited available water resources, and how this can lead to serious threaten to the sustainability of the crop production sector, and thus the future of food security by 2030 . Finally, this work will represent some important solutions and recommendations for decision makers, in order to save the future of food security in the UAE.

\section{Irrigation Resources in the UAE}

Currently, there are three main fresh water resources in the UAE, groundwater (4,052 million $\left.\mathrm{m}^{3}, 70 \%\right)$, desalinated water $\left(950\right.$ million $\left.\mathrm{m}^{3}, 24 \%\right)$ and treated wastewater (319 million $\mathrm{m}^{3}, 6 \%$ ), as illustrated in Figure $1[1,7,9]$. According to the world bank [9], the agricultural sector alone consumes about $83 \%$ of the total water demand of the country comparing to the domestic and industrial sector [10].

Over time, the agricultural sector showed huge expansion in water consumption; from 950 million $\mathrm{m}^{3}$ in 1990 [10] to 3,320 million $\mathrm{m}^{3}$ in 2010 [11], as represented in Table 1 . This was essential to cover the sharp population growth in the UAE, as illustrated in Figure 2 [12], which was 
extremely increased around 40 folds in just 4 decades, from 231,529 in 1970 to $9,346,129$ in 2013 [1]. Besides, the concept of "desert greening" was a great motivator to enlarge the agricultural sector and turn the arid desert into green paradise [12].

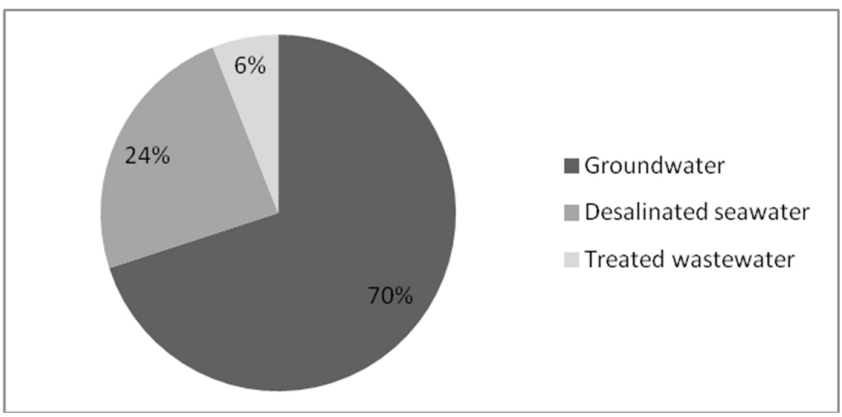

Figure 1. Water resources in the UAE

Table 1. Assessing water demands by agricultural sector in the UAE [10; except a: 11]

\begin{tabular}{|c|c|}
\hline Year & Agriculture (million $\mathrm{m}^{3} /$ year) \\
\hline 1990 & 950 \\
\hline 1995 & 1,300 \\
\hline 2000 & 1,400 \\
\hline 2005 & $3,323^{\mathrm{a}}$ \\
\hline 2010 & $3,320^{\mathrm{a}}$ \\
\hline
\end{tabular}

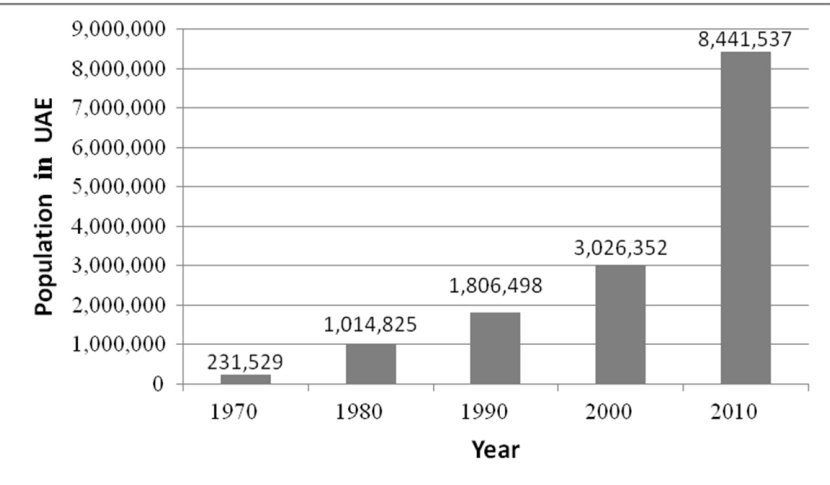

Figure 2. Population growth in the UAE

\subsection{Conventional Irrigation Resources}

In fact, groundwater is the main conventional water resource in the UAE [10], which is extremely used to cover two sectors; the forestry and the agricultural sector [8]. Unfortunately, the high dependency in this non-renewable water resource, with the huge consumption rates comparing to recharging ones, have led to severe problems, related to saline water intrusion [14] and the significant depletion in the groundwater levels up to 60 meters. Creating real concerns that groundwater would soon dry out and vanish [13].

\subsection{Non-Conventional Irrigation Resources}

Recently, the non-conventional water resources have attracted great attention in the UAE; in order to cover the huge water demand, including seawater desalination and domestic wastewater treatment [10]. However, desalinization plants are extremely expensive, in terms of construction and maintenance (more than US\$2 billion). In addition, they have many negative environmental impacts, related to global warming and threatening the marine biodiversity [13]. On the other hand, domestic wastewater treated by high treatment standards, up to secondary and tertiary levels, could be reused and recycled safely at cost effective rates, thus act as an attractive sustainable solution to the fresh water scarcity $[7,15,16]$.

\section{Old and New Irrigation Methods}

In fact, all the agricultural lands in the UAE are $100 \%$ irrigated [8]. In the past, all agricultural lands were irrigated using traditional irrigation methods, including flood, furrow and aflaj systems. Today, modern irrigation techniques are used, such as, localized, surface and sprinkler irrigation systems $[7,8]$. These new technologies were introduced in the mid of 1980s [13] and greatly contributed to save around $60 \%$ of the water comparing to the old applied methods [8].

In $\mathrm{Abu}$ Dhabi, the total irrigated area of the farms was around 199,414 ha in 2003. Irrigation practices include, drip $(74.5 \%)$, bubbler $(12 \%)$, sprinkler $(10.8 \%)$ and other localized irrigation practices $(2.7 \%)$, as represented in Figure $3[8,17]$.

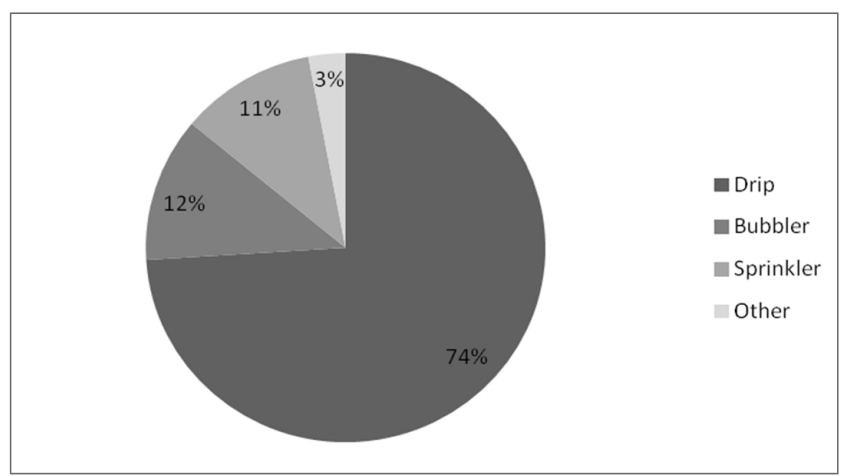

Figure 3. Irrigation practices in Abu Dhabi

\section{The Sever Competition on the Limited Irrigation Resources}

The green sector in the UAE is divided into two sectors; the forestry and the agricultural sector. The forestry sector is responsible for the landscaping purposes, and the agricultural sector is responsible for the crop production purposes [8].

Based on the latest data mentioned in the water resources master plan, which was published by the Abu Dhabi Environmental Agency (2009) [13], the total annual amount of water withdrawal by the two sectors was estimated to be 
around 2,198 million $\mathrm{m}^{3}$. Out of this amount, around $32.25 \%$, was consumed by the forestry sector and the rest amount, around $67.75 \%$, was consumed by the agricultural sector for crop production purposes, as illustrated in Figure 4. This means that, although the fresh water resources are scarce in the UAE, one-third of the total water amount is used for landscaping purposes only.

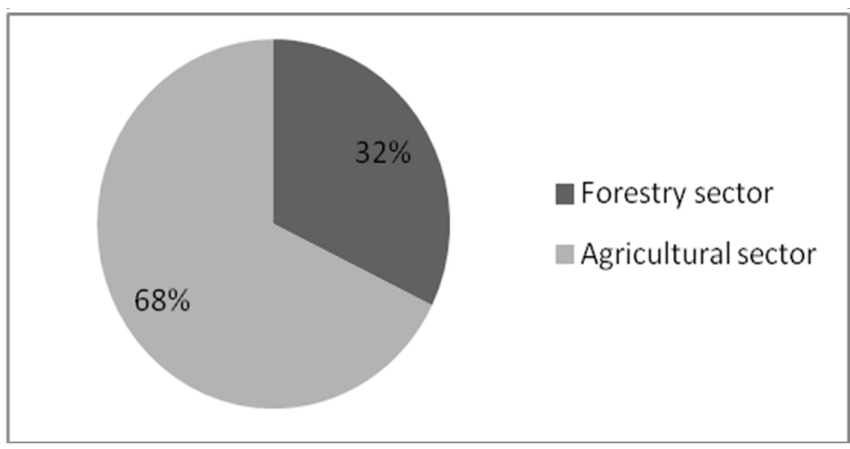

Figure 4. Water withdrawal by the green sector in the UAE

Annually, the forestry sector consumes at least around 709 million $\mathrm{m}^{3}$. This amount of water is used for irrigating the landscaping, such as, the street plantations and parks. This sector is responsible for the beauty of the country and very attractive for the tourism sector. The main resources that covers the watering requirements for this sector are the groundwater and the treated domestic wastewater, which contribute to irrigate watering amounts estimated to be 579 million $\mathrm{m}^{3}(81.7 \%)$ and 130 million $\mathrm{m}^{3} \quad(18.3 \%)$, respectively $[13,17]$, as illustrated in Figure 5.

The agricultural sector consumes around 1,489 million $\mathrm{m}^{3}$ per year. This amount of water is used to irrigate the agricultural crops, which contribute to the plants based food production, and thus food security in the country. The main resources that covers the watering requirements for this sector are the groundwater and the desalinated sea water, which contribute to irrigate watering amounts estimated to be 1,413 million $\mathrm{m}^{3}(94.9 \%)$ and 76 million $\mathrm{m}^{3}(5.1 \%)$, respectively $[13,18]$, as illustrated in Figure 5.

It worth mentioning that, the main watering resource for the green sector in the UAE is the groundwater $[7,10,16]$, which contributes to irrigate $81.7 \%$ and $94.9 \%$ of the forestry and the agricultural sector, respectively, as illustrated in Figure 5.

However, the groundwater resource is a non-renewable water resource. Besides, it's expected to dry out and vanish within the next 16 to 36 years [12]. In addition, the consumption rates from the groundwater are expected to grow sharply in an accelerated rates; in order to cover the extensive watering needs of the green sector.

The reasons are mainly to go in parallel with the sharp population growth, which is expected to reach above 12 million by $2030[13,16,17]$. Taking in consideration that, the UAE is becoming a very attractive location for many international occasions, such as, Dubai EXPO 2020. Consequently, sever pressure will be added soon on the limited irrigation resources, which sustain the green sector and the crop production sector in specific. Thus, the sustainability in this context is a controversial topic and a critical challenge.

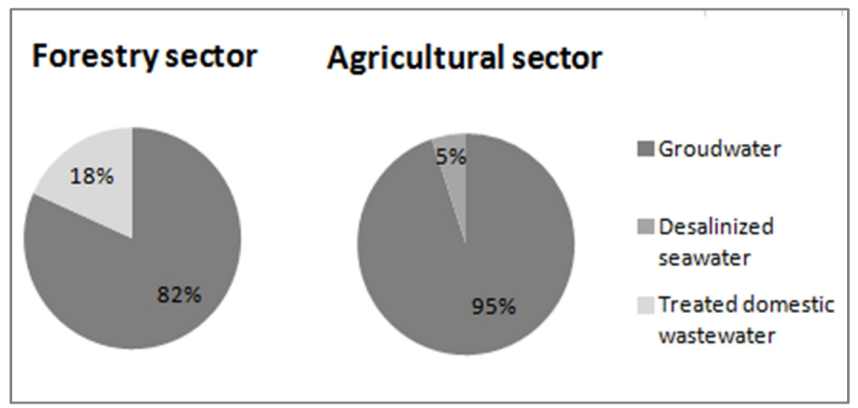

Figure 5. Main water resources consumed by the forestry and the agricultural sector in the UAE

\section{Food Security Challenges by 2030}

It worth to be mentioned that, since the UAE is not an agricultural country, thus using the term of "food security" is just meant to be a relative food sufficiency. Most of the agricultural commodities available in the market, which require enormous amounts of water, are imported.

However, the country invests huge efforts in the crop production field; to achieve partial food security, as much as possible. For example, the UAE is among the top exporters for dates, which have great nutritional and traditional values, and thus significant economical impacts in the country [7].

In 2030, the population in the UAE is expected to be doubled comparing to the population in 2007, reaching at least 12 million [18,19]. Therefore, if the watering requirements supplied by the groundwater for food production was estimated to be around 1,413 million $\mathrm{m}^{3}$ in 2007 [13], then the projected watering requirements needed to reach food security in 2030 will be, at least, 2,826 million $\mathrm{m}^{3}$ annually. This will be the case if the consumption rates from the groundwater aquifers stayed at same rates estimated in 2007. Otherwise, the real expected situation would be much worse, and these figures would be underestimated.

At the same time, the remaining life time expectancy for the available groundwater aquifers is estimated to be between 16 to 36 years $[13,17,18]$. Meaning that, the year 2030 , could be the first year with no more supply from groundwater resources. Leaving the future of food security in the UAE in a real challenging situation.

Although, the country landscaping beauty plays a very significant role in the era of urbanization, however, this worth nothing comparing to a life fundamental requirement, which is the food production and security. Meaning that, while seeking for an alternative solution to cover over 2,826 million $\mathrm{m}^{3}$ yearly from watering requirements, the landscaping sector will be a serious competitor to the crop production sector in the country.

According to many recent studies, wastewater can be 
used after adequate treatment, up to tertiary levels, in irrigating agricultural crops [20-24], such as, irrigating the most important economical tree in the UAE, which is the date palm $[7,25]$. Nevertheless, since the UAE is one of the most rich countries in the world, from oil revenue [2], and based on cultural and religious thoughts, treated domestic wastewater is not used in the country for crop production purposes, and used mainly by the forestry sector and for landscaping purposes $[10,26,27]$. Although, there are currently increasing interests to start using this valuable resource for crop production purposes [13].

Putting aside the social aspect on the application of treated domestic wastewater, the total available treated domestic wastewater in the UAE, which was estimated by the Abu Dhabi Environmental Agency [13], was around 289 million $\mathrm{m}^{3}$ in 2007. At the same time, the total irrigation requirements for the date palm plantations only was approximately 320 million $\mathrm{m}^{3}$ in $2007[7,28]$. This means that, if all the treated domestic wastewater used to irrigate date palm trees only, it will not be enough. Although, this resource is a sustainable and cost effective resource, however, it can cover very small percentage from the total watering needs [7].

\section{Recommendations for Decision Makers}

The key solution, that can best mitigate the expected sever water shortage from groundwater resources, can be done through following five main aspects; First, application of the water has to be based on priority use. Thus, watering the crop production sector has more priority comparing to watering the forestry and landscaping sector $[13,18]$.

Second, cultivation of indigenous and naturalized plants, cultivated for either food or ornamental purposes, could save enormous amounts of water. These deserts plants have amazing potentials to adapt the harsh environmental conditions; including the drought and soil salinity [29]. Additionally, most of these plants have powerful medicinal and therapeutic values, which have many evidences from the traditional medicine, and thus act as a rich phytochemicals resource for the country [29-31]. On the other hand, crops, which consume huge amounts of water, could be imported from outside country, instead of cultivating them locally.

Third, irrigation management, through adoption the best agricultural practices and irrigation methods, including deficit irrigation and irrigation scheduling, in order to reduce watering amounts, increase water use efficiency and increase water productivity. Here it worth mentioning that, more efforts have to be done related to irrigation scheduling through optimization models; to reach the maximum yield with minimal drops. Taking in consideration, the climatologically factors and climate change $[13,16]$. Moreover, monitoring systems have to be installed; in order to achieve the following; minimize the water use, avoid over pumping from groundwater aquifers, avoid over irrigation practices and to control the water lost by leaking problems [13].

Fourth, strategic planning and development, which could be done through, taking positive actions to reduce irrigation requirements (e.g. increase water use efficiency and water productivity), irrigating with mixture from saline water and brackish water mixed up to acceptable limits, using the treated domestic wastewater and lastly developing the planning and development sector, through adoption and implementation of the best practices worldwide in water planning and development, such as, Australian's expertise [13].

Fifth, the community in the UAE has essential role to save more drops per crops. Thus, educating and raising the awareness level for them to be aware about the expected critical challenges and available solutions, that can rescue the food production sector, is very crucial, in order to reach food security in the country, as well as, to save and sustain this sector for the futures generations.

\section{Future Research Directions}

\subsection{Advancements in the Water Use Efficiency}

Hardly works have to be done for optimization (optimization models) of the irrigation schedules; in order to apply the minimal watering volumes with maximal acceptable yields. Taking in consideration, the climatologically conditions and climate change [11].

\subsection{Wastewater Application}

Indeed, treated domestic wastewater, which treated using high treatment standards, up to secondary and tertiary levels, could be reused and recycled safely at cost effective rates. Therefore, act as an attractive and sustainable solution to reuse and recycle the water already exists, and thus contributes to mitigate fresh water scarcity in the country [20-24].

In the UAE, since the future of water resources is challenging, thus it is necessarily to study the influence of treated domestic wastewater on the growth and productivity of the economical crops. Safety aspects play vital role in this area. Moreover, it's very important to match between the quality of the treated wastewater and the needed application $[32,33]$. For example, high quality water has to be used for food production purposes, while low quality ones could be used for landscaping $[7,13,16]$.

Moreover, more efforts have to be done on groundwater replenishing, through injecting the groundwater aquifers with treated domestic wastewater. As an attempt for enhancing their levels and increasing the period of their life spans $[10,34]$.

\subsection{Exploring New Energy Resources}


Another fundamental research area is to explore the possibilities of using the nuclear power as a sustainable energy resource to do seawater desalination. Also, seeking for the implementation of sustainable energy resources, like nuclear and solar energy, for desalination purposes. Positive results of such studies could open the doors for new significant resources for irrigating the green sector of the country.

\subsection{Climate Change and Global Warming}

Since, the climate change and global warming is one of the top and hot topics in the agricultural field $[35,36]$. Then, the country has to conduct big funded research projects at large scale; in order to evaluate the capability of different economical crops on adapting the climate change matter. For example, investigating different varieties of date palm trees under climate change and global warming.

The conclusion of such research projects will provide potential feedback and will enable decision makers to take appropriate decisions related to cultivating tolerated crops, that can tolerate elevated levels of temperatures and carbon dioxide [35, 36], and consequently will guarantee sustainability of the crop production sector in the country.

\section{Conclusions}

In the UAE, the future of the agricultural sector is very challenging in terms of irrigation requirements. There is a severe competition between the forestry and the agricultural sector, which is highly expected to continue with further increasing, especially with the sharp population growth in the country.

The main future concern related to food security in the $\mathrm{UAE}$ is when the watering requirements, that supply the crop production sector greatly increased, while the groundwater supplies would be stopped.

In 2030, the total predicted watering requirement depending on the groundwater resources for crops production would be approximately 2198 million $\mathrm{m}^{3}$ annually. On the other hand, the same year could be the first year with no more supply from groundwater resources. Leaving the future of the agricultural sector in a real critical situation.

As a result, quick actions have to take place in order to save the future of the agricultural sector and food security in the country. This can best be done through applying five key solutions; First, application of the water has to be always based on priority use. Second, cultivating indigenous and naturalized crops, that can tolerate drought and saline conditions. Third, irrigation management. Fourth, strategic planning and development. Fifth, activating the community role.

Finally, it's very clear from this work that, any further expansion in the green sector of the UAE have to be done under absolute control and have to be cautiously evaluated and managed from decision makers; in order to best fulfill the sustainable approach for the future of the green sector in the country.

\section{REFERENCES}

[1] The World Bank. World development indicators: data for United Arab Emirates, Washington, USA, 2014.

[2] Ministry of Information and Culture. UAE Yearbook, Abu Dhabi, UAE, 2010.

[3] Food and Agriculture Organization of the United Nations (FAO). Water report: irrigation in the near east region in figures, Rome, Italy, Rep. 9, 1997.

[4] Ministry of Environment and Water (MEW). Agriculture information center, Dubai, UAE, 2005.

[5] A. O. Mohammed, S. M. Shahin. Impact of Soil Magnetic Properties on Moisture Content Prediction Using TDR, Geotechnical Testing Journal, vol. 34, pp. 273-278, 2011.

[6] S. M. Shahin, H. Ghamlouche, A. O. Mohammed. Dependency of Dielectric Permittivity on Iron and Iron-bearing Minerals Content in Soil, Proceedings of the 10th UAE University Annual Conference, Al Ain, pp. 726-735, 2009.

[7] S. M. Shahin, M. A. Salem. Review future concerns on irrigation requirements of date palm tree in the United Arab Emirates (UAE): call for quick actions," The 5th International Date Palm Conference, Abu Dhabi, UAE, 2014.

[8] Food and Agriculture Organization of the United Nations (FAO). Irrigation in the middle east region in figures, AQUASTAT survey: United Arab Emirates, FAO, Rome, Italy, 2008.

[9] The World Bank. Annual freshwater withdrawals, total (billion cubic meters): data for United Arab Emirates, Washington, USA, 2013.

[10] A. A. Murad, H. Al-Nuaimi, M. Al-Hammadi. Comprehensive assessment of water resources in the United Arab Emirates (UAE), Water Resources Management, vol. 21, pp. 1449-1463, 2007.

[11] FAO (Food and Agriculture Organization of the United Nations). Aquastat: data for United Arab Emirates, Rome, Italy, 2013.

[12] The World Bank. World development indicators: data for United Arab Emirates, Washington, USA, 2012.

[13] EAD (Environmental Agency of Abu Dhabi). Abu Dhabi water resources master plan, Abu Dhabi, UAE, 2009.

[14] W. Al-Zubari. Towards the establishment of a total water cycle management and re-use program in the GCC countries, Desalination, vol. 120, pp. 3-14, 1998.

[15] The World Bank. Introduction to wastewater treatment processes, Washington, USA, 2011.

[16] S. M. Shahin, M. A. Salem. Water governance through regulations and responsibilities in the United Arab Emirates 
UAE, The International Water Summit, Abu Dhabi, UAE, 2013.

[17] S. M. Shahin, M. A. Salem. The cost of landscaping beauty in the United Arab Emirates (UAE): Call for quick actions to save the irrigation resources, in Proceedings of ICMTSET 2014, Dubai. Zelus International. ISBN 9789383303816, 2014.

[18] S. M. Shahin, M. A. Salem. Food security in the United Arab Emirates (UAE): The great competition between the agricultural and forestry sector on irrigation resources, in Proceedings of IRCSHM 2014, Dubai. Mudranik Technologies Pvt. Ltd. ISBN 9789383303908, 2014.

[19] The World Bank. Population estimates and projections: United Arab Emirates, Washington, USA, 2012.

[20] B. Sheikh, R. P. Cort, W. R. Kirkpatrick, R. S. Jaques, T. Asano. Monterrey wastewater reclamation study for agriculture, Research Journal of the Water Pollution and Control Federation, 1990.

[21] T. Asano, A. D. Levine. Wastewater reclamation, recycling and reuse: past, present, and future, Water Science and Technology, vol. 33: 10-11, pp. 1-14 (special issue), 1996.

[22] W. Van der Hoek, M. U. 1-Hassan, J. H. J. Ensink, S. Feenstra, L. Raschid-Sally, S. Munir, M. R. Aslam. Urban wastewater: a valuable resource for agriculture, International Water Management Institute Research Report, Colombo, vol. 63, 2002.

[23] D. W. York, R. Holden, B. Sheikh, L. Parsons. Safety and suitability of recycled water for irrigation of edible crops, In: Proceedings of the 23rd Annual Water Reuse Symposium, Water Reuse Association, Dallas, 2008.

[24] F, Pedreroa, I. Kalavrouziotisb, J. J. Alarcóna, P. Koukoulakisb, T. Asanoc. Use of treated municipal wastewater in irrigated agriculture: Review of some practices in Spain and Greece, Agricultural Water Management, vol. 97, pp. 1233-1241, 2010.

[25] FAO (Food and Agriculture Organization of the United Nations). Water report: the wealth of waste: The economics of wastewater use in agriculture, Rome, Italy, Rep. 35, 2010.

[26] ADSSC (Abu Dhabi Sewerage Services Company). ADSSC annual report 2007, Abu Dhabi, UAE, 2007.

[27] ADSSC (Abu Dhabi Sewerage Services Company). ADSSC annual report 2010, Abu Dhabi, UAE, 2010.
[28] Food and Agriculture Organization of the United Nations (FAO). Workshop on Irrigation of date palm and associated crops, Proceedings of the Regional office for the Near East, Cairo, Egypt, 2008.

[29] S. M. Shahin, M. A. Salem. Four reasons will convince the landscape decision makers to go for indigenous plants in the United Arab Emirates (UAE), International Journal of Recent Development in Engineering and Technology, vol. 3, no. 1, pp. 1-8, 2014.

[30] S. M. Shahin, M. A. Salem. The lifeline rescuers of tomorrow's landscaping in the United Arab Emirates (UAE): All the hope rests on the indigenous plants, in Proceedings of ICMTSET 2014, Dubai. Zelus International. ISBN 9789383303816, 2014.

[31] H. K. Ali, A. J. Cheruth, M. A. Salem, S. Maqsood. Evaluation of antioxidant activity of Cleome brachycarpa Vahl ex DC, an under-exploited desert plant of the United Arab Emirates. Pharmacology Online 3, 125-131, 2012.

[32] S. M. Shahin, M. A. Salem. Extracting Therapeutic Grade Essential Oils from the Lamiaceae Plant Family in the United Arab Emirates (UAE): Highlights on Great Possibilities and Sever Difficulties. World Academy of Science, Engineering and Technology, International journal of Biology, Veterinary, Agricultural and Food Engineering, vol. 8, no. 12, pp. 1223-1228, 2014.

[33] S. M. Shahin, M. A. Salem. Extracting therapeutic grade essential oils from the Lamiaceae plant family in the United Arab Emirates (UAE): Highlights on great possibilities and sever difficulties. Proceedings of the XII International Conference on Medicinal and Aromatic Plants (ICMAP) 2014, Malaysia, 4-5 December, 2014.

[34] S. M. Shahin, M. A. Salem. The five key solutions to rescue the landscaping sector in the United Arab Emirates (UAE). Discovery Publication. vol. 25, no. 88, pp. 41-47. 2014. ISSN 2278-5469. EISSN 2278-5450.

[35] M. A. Salem, V. G. Kakani, and K. R. Reddy. Temperature effects on in vitro pollen germination and pollen tube growth of soybean genotypes. Annual meetings of the Southern Branch of the American Society of Agronomy. 2004.

[36] M. A. Salem, V. G. Kakani, S. Koti and K.R. Reddy. Pollen-based screening of soybean genotypes for high temperatures. Crop Science, vol. 47, no. 1, pp. 219-231, 2007. 